\title{
A Comparison of LUCC Detection Algorithms in a Mesoamerican Lowland Tropical Forest
}

\author{
LAUREL SUTER, DAVID LÓPEZ-CARR \\ University of California, Santa Barbara, Department of Geography
}

\begin{abstract}
Land use and land cover changes occur throughout the world, but none is more concerning than tropical deforestation, much of it for agricultural purposes. Rural-rural frontier migrant farmers such as those colonizing the Sierra del Lacandón National Park in Petén, Guatemala act as a primary direct agent in this land cover conversion. This paper seeks to compare three different algorithms for monitoring changes in forested land cover, making use of freely available remotely sensed Landsat images from two years, 1991 and 2000. In the intervening 9 years, some forested land was converted to cropped, pasture, or fallow land, while other areas experienced no change. This paper contains a detailed description of the methods employed for three different change detection techniques, producing a total of five land change maps: multidate principal components analysis (PCA), normalized difference vegetation index (NDVI) image differencing, and brightness greenness wetness (BGW) image differencing. Of the five land change maps produced, the Greenness component of the BGW transformation had the highest overall accuracy, at $86 \%$, and is conservative in detecting change. The amount of change detected by this algorithm represents approximately $300 \mathrm{~km}^{2}$ of forest loss, or $11.9 \%$ of the area examined.
\end{abstract}

Key words: LUCC, Landsat, PCA, NDVI, BGW

\section{Background and Objectives}

Land use and land cover changes occur throughout the world, but none is more concerning than tropical deforestation, which threatens biodiversity, releases greenhouse gases, and undermines the sustainability of local environments and of food production systems (Ojima, Galvin et al. 1994; Bongaarts 1996). Land clearing for agricultural purposes has been called "the most evident of all human relationships with the physical earth" (Parsons 1994), and indeed comprises the most expansive footprint of human induced environmental change on the face of the earth.

Rural-rural frontier migrant farmers such as those colonizing the Maya Biosphere Reserve (MBR) and within it the Sierra del Lacandón National Park (SLNP) in Petén, Guatemala (Figure 1) act as the primary direct agents in this land cover conversion (Rudel and Roper 1996; Geist and Lambin 2001; United Nations 2001). Increasingly, 
frontier deforestation of this kind encroaches into biodiversity-rich "protected" areas (FAO 2005). As the amount of land protected in conservation reserves expands (an estimated increase of 96 million hectares between 1990 and 2005, for a total of $11 \%$ of the total forested area (Brandon and Wells 1992; Rudel and Roper 1996), the amount of unoccupied land outside of reserves likewise decreases, prompting a subset of the rural poor to increasingly seek land and refuge within these strikingly biodiverse areas (Carr 1999). Starting in the late 1980's, arriving waves of colonists within the SLNP are estimated to have reached 20,000 individuals by 1999 , with a $70 \%$ annual growth rate estimated between 1993 and 1998 (Carr 2002). Concomitantly, approximately $11 \%$ of the park's forest canopy has been eliminated, 9\% since 1990 (Turner II, Meyer et al. 1994; Geist 1999).

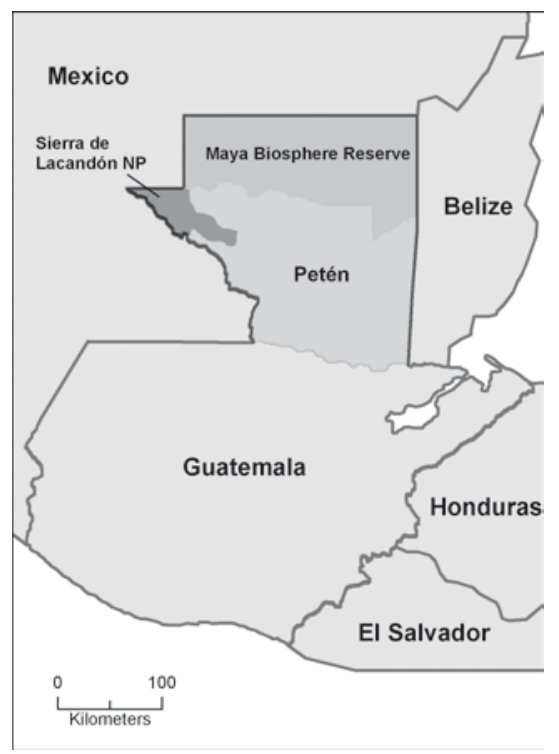

Fig. 1 Area of interest

Most land cover changes within these protected areas consist of a limited number of types: forest converted to cleared land and cleared land allowed to regrow into forest, either for a fallow period or upon permanent abandonment. The topic discussed here, monitoring changes in forested land cover is directly applicable for input into such applications as global carbon cycle modeling. As the agents of these changes, human-induced land use/cover change (LUCC), especially in the tropics, is increasingly recognized as a critical priority of the global environmental change research agenda (Turner II, Meyer et al. 1994; Geist 1999). When combined with socio-economic data, monitoring land cover changes of these types also serves to help tease apart the human drivers of these conversions for further biogeochemical forecasting efforts, as well as for policy recommendations regarding rural sustainability and food security.

Change detection seeks to establish that changes in the land covers of interest will result in changes in the at-sensor reflectance values recorded, independent of potential 
variables exterior to land cover differences such as atmospheric conditions, illumination, or viewing angle. Spatial, spectral, thematic and temporal constraints inherent in change detection coupled with the wide array of change detection techniques available make selecting a project-appropriate algorithm challenging, with potentially profound impacts on the quality of the resultant change-detection product ( $\mathrm{Lu}$, Mausel et al. 2004).

Acknowledging this, we performed change detections using different algorithms on a portion of the Maya Biosphere Reserve and compared their efficacy for accurately identifying areas of change in which forest was cleared in comparison to areas of no change. Although Hayes and Sader (2001) were able to identify areas of forest regrowth in a neighboring scene (Landsat TM path/row 20/48), regrowth proved to be negligible within the area examined here and thus was omitted as a change class of interest. We made use of three different change detection techniques, producing a total of five land change maps: multidate principal components analysis (PCA), normalized difference vegetation index (NDVI) image differencing, and brightness greenness wetness (BGW) image differencing.

\section{Data}

We acquired two Landsat images (Table 1) for path/row 21/48 for two different time periods spanning 9 years, covering a portion of the northern Guatemalan departamento of Petén and the southern Mexican states of Chiapas and Tabasco from the University of Maryland's Global Land Cover Facility. The temporal coincidence between image acquisition dates (April 3, dry season) should reduce scene to scene variation from differences in sun angle and vegetation phenology.

Table 1 Data used in analysis

\begin{tabular}{|c|c|c|}
\hline Acquisition Date & Dataset & Condition \\
\hline 3-Apr-1991 & TM & Clear \\
\hline 3-Apr-2000 & ETM + & Hazy \\
\hline
\end{tabular}

Differences between images may result, however, from the presence of a smoky haze (albeit relatively evenly distributed across the area of interest and therefore to a certain extent correctable) in the image from 2000, as well as differences in soil moisture and plant vigor. Visual inspection within the 2000 image of reduced stream flows and standing water volume across the landscape mark an independently corroborated drought within the area of interest in comparison to the 1991 image. Indeed, the smokiness of the 2000 image may be attributable to increased agricultural burning, controlled or not, under drought conditions. Ideally, scenes should be acquired with the same sensor and not two different ones as done here with the TM and ETM+ sensors. Hence not all changes detected between images dates may be directly attributable to human modification of land cover. Preprocessing of the images and careful comparison of the efficacies of each of the proposed change detection algorithms aims to keep these confounding factors to a minimum. 


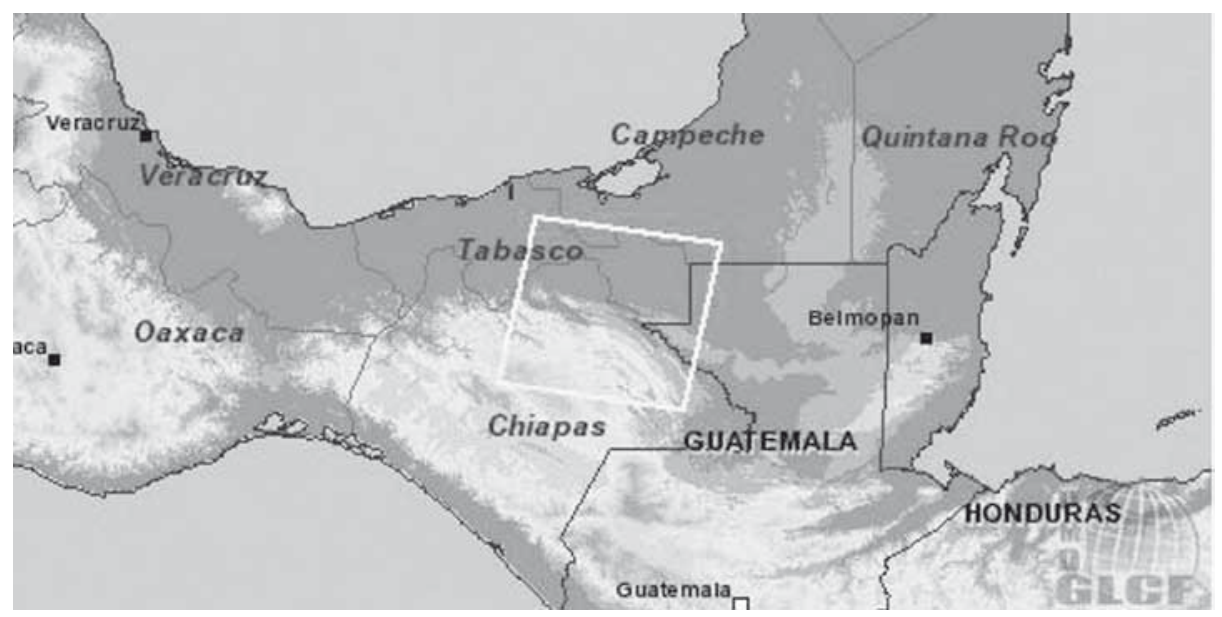

Fig. 2 Location of path/row $21 / 48=$ map 2

The images in question were acquired already georeferenced and orthorectified. Atmospheric correction, however, was necessary to minimize the impact of smokiness in the 2000 image. The smoke was relatively evenly distributed across the portion of greatest interest in path/row 21/48 (depicted as box in Figure 2), the part falling within the borders of Guatemala and comprising portions of the SLNP and the MBR; it was less evenly distributed across other portions of the scene. For that reason, and also to reduce data volume for increased accuracy and computational efficiency, the scenes were subset so only the portions of 21/48 of interest, the ostensibly protected lands within the SNLP and MBR, remained. At the same time, major water features were also masked.

Relative atmospheric and radiometric correction was performed for bands 1-5 and 7 . A dozen invariant normalization targets were selected across the range of DN values for band 1 between the two time periods, which were used to calculate an empirical line for correcting DN values of the smoky 2000 image to be more in line with those taken in 1991. An example of corrected pixel values is shown in Figure 3, which compares a scatter plot of the 1991 master and 2000 subject images before and after radiometric correction. The shape of the plot is unchanged, but upon correction the range of the y-axis denoting DN values of the subject image is brought more in line with the range of the master image.

All bands of the subject 2000 image were corrected for atmospheric and radiometric differences for their inclusion in the three different change detection methods. The BGW differencing change detection algorithm employed all bands. A layered spectral subset of the corrected bands 3 (visible red), 4 (NIR), and 5 (mid-infrared) were used for the multidate PCA and NDVI differencing algorithms in order to reduce betweenband correlation, data volume, and processing time (Hayes and Sader 2001).

With the change detection algorithms discussed here, thresholds for determining change in the tail of the resultant histogram of DN values versus no change towards the middle of the histogram were set in an interactive and independent fashion until the 

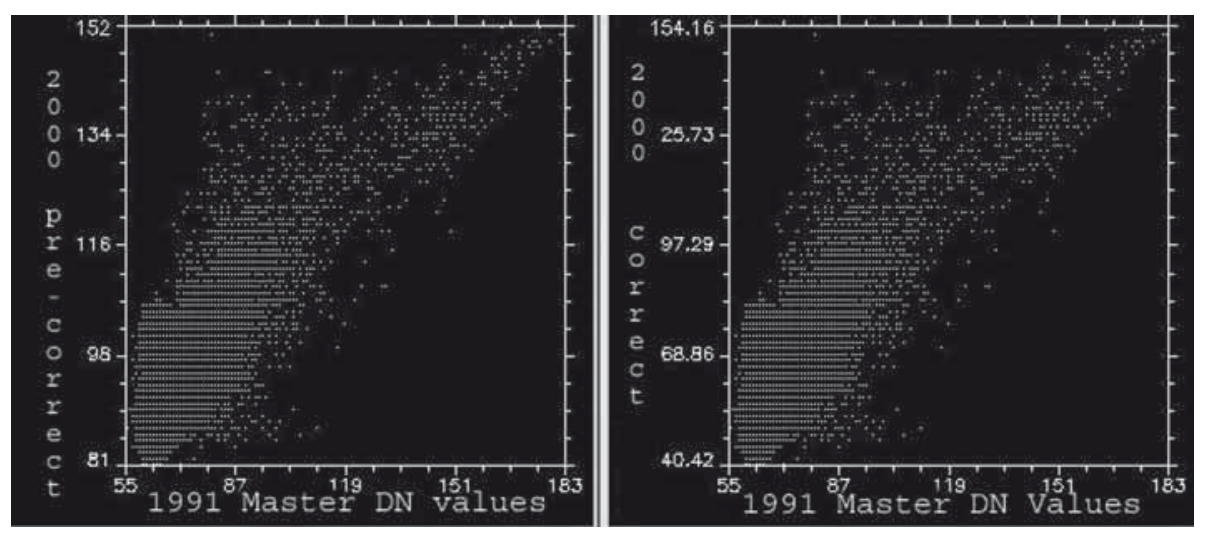

Fig. 3 Pre- and post-radiometric correction scatter plots

Kappa coefficient of agreement, which is a measure of the agreement between a classification map and reference data (Congalton 1991), was maximized for each category. Therefore validation points must be determined at the outset and used for final change detection map production (Hayes and Sader 2001).

Validation points were selected by creating a NDVI difference map which was classified with an unsupervised k-means algorithm into 12 change classes, which were then used for equalized stratified random sampling, each of the 12 classes providing 10 pixels for a total of 120 validation points. These points were overlain on a RGB-321 display for both dates for visual inspection and classification as change or no change. Although it has been demonstrated that RGB-453 is preferable for visualizing agricultural activity, agricultural plots were easily confounded with the extensively fire-scarred but still forested areas using this visualization scheme and therefore RGB321 was used. Thresholds between the two change classes were repeatedly set and evaluated via a confusion matrix, with the threshold level chosen based on a maximization of the Kappa coefficient of agreement between the classified change image and the reference data. These reference points were independent of the pixels used for the final accuracy assessments of the change maps produced by each method.

\section{Change Detection Algorithm 1: Multidate PCA}

One algorithm for consideration in a change detection exercise is the multidate PCA transformation that has been used by Jha and Unni (1988) in monitoring tropical forest conversion. Following the approach used by Conese et al. (1988), bands from both dates of interest (in this case bands 3, 4, 5 from 1991 and 2000) are combined into a single file and then transformed to create new, uncorrelated images. Hayes and Sader (2001) found a standardized routine employing the correlation matrix to be preferable to a PCA employing the covariance matrix in applications such as this. The output matrix of eigenvectors shows between-date correlation for each band for each component, with change usually represented by a lack of correlation among bands between dates. Eigenvectors with sign changes among band weights between dates 
may represent real land cover change between times. Hayes and Sader (2001), using this algorithm on neighboring path/row (20/48) TM scenes to those under consideration here (21/48), found components 3 and 4 to meet this change of sign criteria, to follow patterns associated with physical changes in "greenness" and "brightness" respectively, and to show high spatial discontinuity in the areas of interest. Table 2 detailing the eigenvectors from the standardize PCA transformation of the data under consideration do indeed demonstrate a sign change in components 3 and 4 between the two dates.

Table 2 Eigenvector Matrix (from Correlation Matrix)

\begin{tabular}{|l|c|c|c|c|c|c|c|c|}
\hline Eigenvector & $\begin{array}{c}\mathbf{1 9 9 1} \\
\text { TM3 }\end{array}$ & $\begin{array}{c}\mathbf{1 9 9 1} \\
\text { TM5 }\end{array}$ & $\begin{array}{c}\mathbf{1 9 9 1} \\
\text { TM5 }\end{array}$ & $\begin{array}{c}\mathbf{2 0 0 0} \\
\text { ETM3 }\end{array}$ & $\begin{array}{c}\mathbf{2 0 0 0} \\
\text { ETM4 }\end{array}$ & $\begin{array}{c}\mathbf{2 0 0 0} \\
\text { ETM5 }\end{array}$ & Eigenvalue & $\begin{array}{c}\text { Proportion } \\
\text { of variation }\end{array}$ \\
\hline Component 1 & 0.16 & -0.31 & 0.47 & 0.26 & -0.47 & 0.61 & 415.94 & 0.51 \\
\hline Component 2 & -0.02 & -0.60 & -0.36 & -0.06 & -0.57 & -0.44 & 240.48 & 0.29 \\
\hline Component 3 & -0.05 & -0.53 & -0.48 & 0.14 & 0.51 & 0.45 & 71.83 & 0.09 \\
\hline Component 4 & -0.24 & 0.49 & -0.59 & 0.16 & -0.43 & 0.37 & 67.60 & 0.08 \\
\hline Component 5 & -0.46 & -0.10 & 0.11 & -0.82 & -0.07 & 0.28 & 14.32 & 0.02 \\
\hline Component 6 & 0.84 & 0.10 & -0.24 & -0.45 & -0.06 & 0.15 & 5.08 & 0.01 \\
\hline $\begin{array}{c}\text { Total } \\
\text { variance: }\end{array}$ & & & & & & & $\mathbf{8 1 5 . 2 6}$ & \\
\hline
\end{tabular}

We elected to further examine only component 3 based on the results reported by Hayes and Sader and the fact that visual inspection revealed a higher degree of spatial discontinuity for component 3 between change classes in our resultant component images. Component 3 was subsequently examined by selecting a threshold between change/no change by maximizing for the Kappa coefficient, and a map of land change classes was created (Figure 4).

\section{Change Detection Algorithm 2: BGW differencing}

Brightness, greenness, wetness differencing based on the Kauth-Thomas (KT) Tasselled Cap transformation is similar in its approach to the PCA in that it reduces redundancy between bands, though in contrast to the PCA this transformation uses scene independent coefficients (Lu, Mausel et al. 2004). The Tasseled Cap transformation is a linear, weighted summation across all TM bands, creating planes of brightness (corresponding to albedo), greenness (contrasting bands 3 and 4 and thus corresponding to a vegetation index), and wetness (showing sensitivity to plant and soil moisture). Differences across each of these indices over time indicate a possible change in land cover, with once again thresholds based on Kappa values necessary to separate each of the different change classes from areas of no change (Seto, Woodcock et al. 2002). 
Collins and Woodcock (1996) found changes in KT wetness to be one of the most reliable single indicators of forest mortality. Difference images were created for each of the BGW transformations, and each was thresholded separately in order to compare their suitability for determining changes in forest clearing between the two dates.

\section{Change Detection Algorithm 3: NDVI differencing}

The normalized difference vegetation index (NDVI) exploits the 'red edge' of vigorous green vegetation and is highly correlated with many vegetation parameters. It has also been shown to be relatively unaffected by topographic factors and is one of few indices with a normal histogram. Image differencing between dates can detect areas of change in canopy cover or biomass (Hayes and Sader 2001). The NDVI for a pixel is calculated based on the equation:

$$
\mathrm{NDVI}=(\mathrm{NIR}-\mathrm{red}) /(\mathrm{NIR}+\mathrm{red})
$$

In the case of Landsat data, the near infrared (NIR) band corresponds to Landsat band 4 and the visible red band corresponds to Landsat band 3. As with the other change detection methods mentioned above, evaluation via Kappa values assists in choosing appropriate thresholds between areas of change and areas of no change.

\section{Accuracy Assessment of Change Detection Maps}

Utilizing each method detailed above, we produced five maps of change classes, delimiting the areas in which deforestation had taken place between 1991 and 2000. To select reference data for accuracy assessment which was representative of the change classes yet not biased towards any particular method, we selected 20 "unchanged" pixels from each map (for a total of 100), and 20 "changed" pixels (again, for a total of 100) from each map, randomized their ordering, and then did a visual comparison between the two dates to determine if the selected points had been cleared or not. We did this until we had evaluated 50 points "changed" and 50 points "unchanged". An excess number of points were chosen (200 instead of the desired 100) because selecting only 50 of each would have resulted in far too few pixels which had actually experienced change in the intervening period. Because their order was randomized before evaluation, no particular method was privileged, however a seldom identified area of change is less likely to be included in the accuracy assessment.

\section{Results}

Presented here are change class maps for each of the three methods presented above, corresponding to a map thresholding for change/no change in PCA band 3 (Figure 4), difference images for between date brightness-greenness-wetness transformations (Figures 5 , 6, and 7), and a difference image for between date NDVI transformations (Figure 8). These figures are followed by Table 3 , which compares their respective accuracy evaluations. 


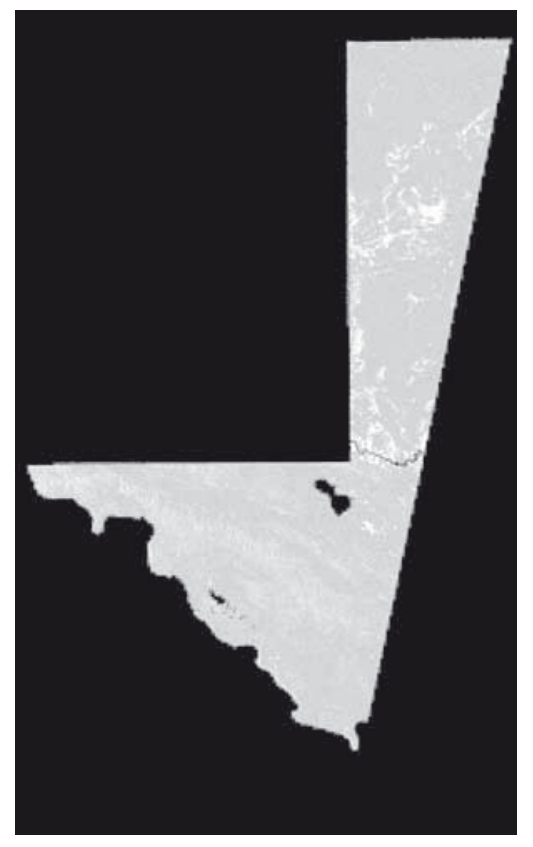

Fig. 4 Change class map PCA band 3 method

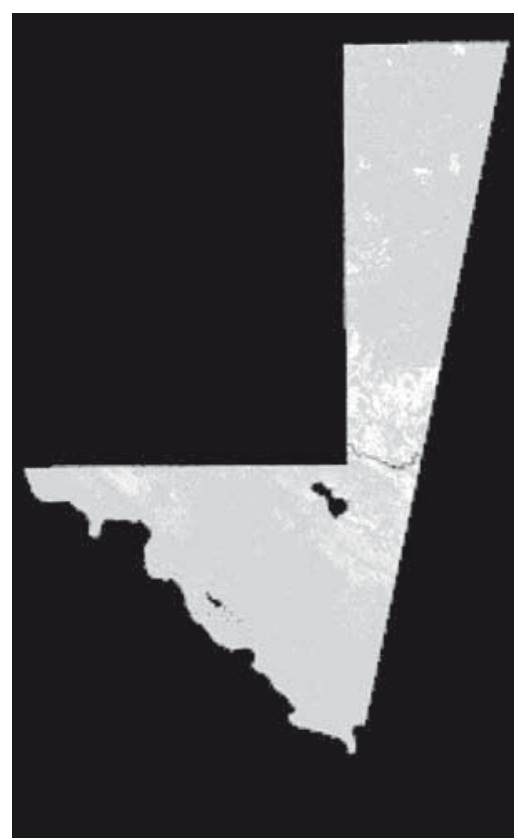

Fig. 6 Change class map Greenness transformation method

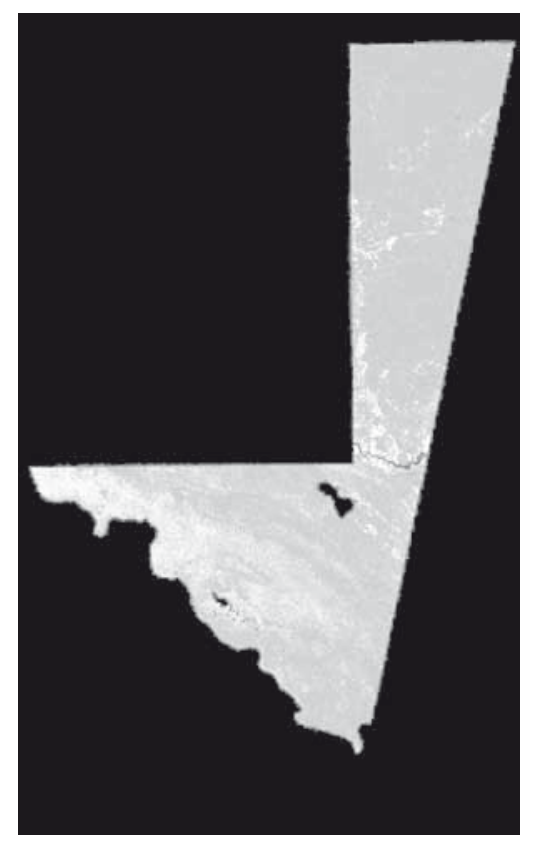

Fig. 5 Change class map Brightness transformation method

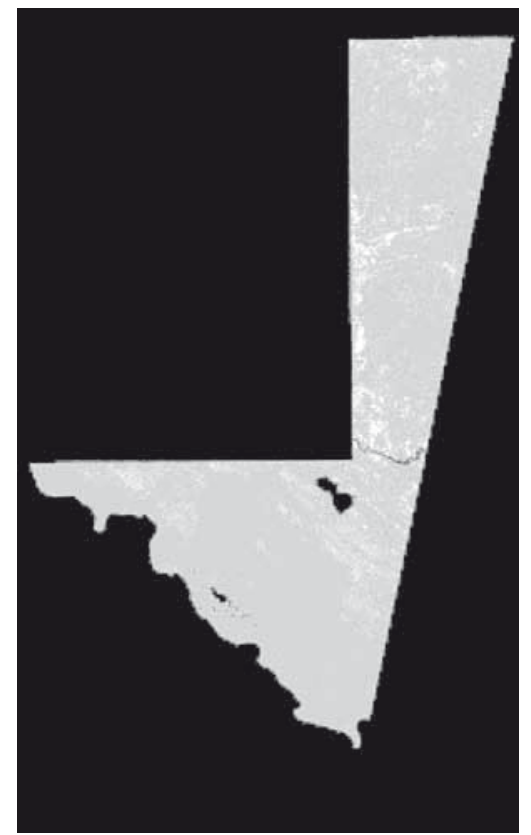

Fig. 7 Change class map Wetness transformation method 


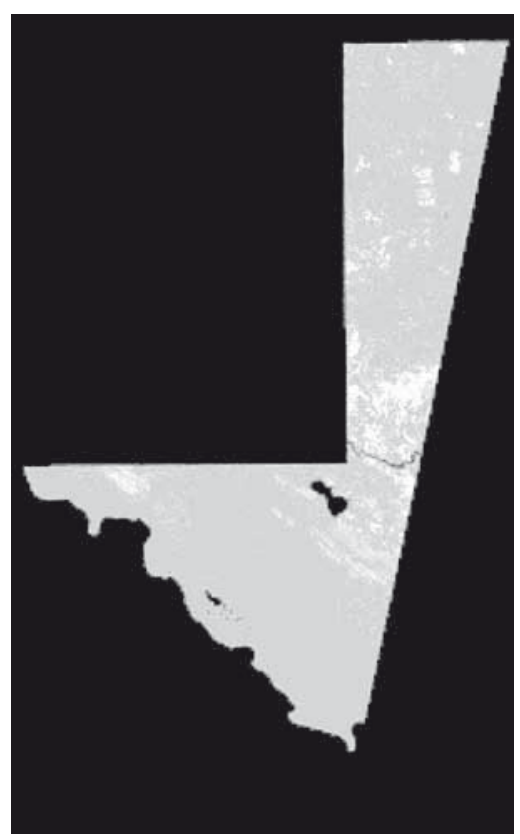

Fig. 8 Change class map NDVI transformation method

Table 3 indicates that the highest overall degree of accuracy and highest Kappa coefficient was achieved with the difference image between the Greenness component of the BGW transformations, with an overall accuracy of $86 \%$ and a Kappa coefficient of 0.72 . This was closely matched by the NDVI difference map, followed by the Wetness difference map, with the Brightness difference map and PCA band 3 map coming in a more distant fourth and fifth place respectively. Tables 4-6 below correspond to the confusion matrices produced during the accuracy assessment of the Greenness-based change class map with the known reference data.

Table 3 Change map accuracies

\begin{tabular}{|c|c|c|}
\hline & Overall accuracy & Overall kappa \\
\hline GREENNESS & $86 \%$ & 0.72 \\
\hline NDVI & $85 \%$ & 0.70 \\
\hline WETNESS & $82 \%$ & 0.64 \\
\hline BRIGHTNESS & $55 \%$ & 0.10 \\
\hline PCA & $54 \%$ & 0.08 \\
\hline
\end{tabular}


Table 4 Greenness Method Accuracy Assessment pixel count

\begin{tabular}{|c|c|c|c|c|}
\cline { 3 - 5 } \multicolumn{2}{c|}{} & \multicolumn{3}{c|}{ Reference Data (pixels) } \\
\cline { 2 - 5 } \multicolumn{2}{c|}{} & Change & No Change & Total \\
\hline \multirow{3}{*}{$\begin{array}{c}\text { Classified } \\
\text { Data }\end{array}$} & Change & 41 & 5 & 46 \\
\cline { 2 - 5 } & No Change & 9 & 45 & 54 \\
\cline { 2 - 5 } & Total & 50 & 50 & 100 \\
\hline
\end{tabular}

Table 5 Greenness Method Accuracy Assessment percentages

\begin{tabular}{|c|c|c|c|c|}
\cline { 3 - 5 } \multicolumn{2}{c|}{} & \multicolumn{3}{c|}{ Reference Data (\%) } \\
\cline { 3 - 5 } \multicolumn{2}{c|}{} & Change & No Change & Total \\
\hline \multirow{3}{*}{$\begin{array}{c}\text { Classified } \\
\text { Data }\end{array}$} & Change & 82 & 10 & 46 \\
\cline { 2 - 5 } & No Change & 18 & 90 & 54 \\
\cline { 2 - 5 } & Total & 100 & 100 & 100 \\
\hline
\end{tabular}

Table 6 Greenness Method Accuracy Assessment Commission and Omission

\begin{tabular}{|c|c|c|c|c|}
\cline { 2 - 5 } \multicolumn{1}{c|}{} & $\begin{array}{c}\text { Commission } \\
(\mathbf{\%})\end{array}$ & $\begin{array}{c}\text { Omission } \\
\mathbf{( \% )}\end{array}$ & $\begin{array}{c}\text { Commission } \\
\text { (pixels) }\end{array}$ & $\begin{array}{c}\text { Omission } \\
\text { (pixels) }\end{array}$ \\
\hline Change & 10.9 & 18.0 & $5 / 46$ & $9 / 50$ \\
\hline No Change & 16.7 & 10.0 & $9 / 54$ & $5 / 50$ \\
\hline
\end{tabular}

Table 7 Greenness Method Producer's and User's Accuracy

\begin{tabular}{|c|c|c|c|c|}
\cline { 2 - 5 } \multicolumn{1}{c|}{} & $\begin{array}{c}\text { Producer's } \\
\text { Accuracy (\%) }\end{array}$ & $\begin{array}{c}\text { User's } \\
\text { Accuracy (\%) }\end{array}$ & $\begin{array}{c}\text { Producer's } \\
\text { Accuracy } \\
\text { (pixels) }\end{array}$ & $\begin{array}{c}\text { User's } \\
\text { Accuracy } \\
\text { (pixels) }\end{array}$ \\
\hline Change & 82 & 89.13 & $41 / 50$ & $41 / 46$ \\
\hline No Change & 90 & 83.33 & $45 / 50$ & $45 / 54$ \\
\hline
\end{tabular}

The Greenness method reveals that $11.9 \%$ of the area examined in this exercise changed from forested to deforested between 1991 and 2000, equivalent to 335,653 out of a total of 2,824,644 pixels. This number of changed pixels represents approximately $300 \mathrm{~km}^{2}$ of deforested area. While the overall accuracy of the Greenness change detection map is $86 \%$, a more nuanced look at the strengths and weaknesses of this algorithm is revealed by breaking down its accuracy by category. The classifier could be called "conservative" in its estimates of areas that had undergone clearing, in the respect that it was more likely to misidentify a "change" pixel as an unchanged area than vice versa. Areas of "no change" had a higher producer's accuracy in comparison to "change", meaning that the instances of "no change" on the ground were more accurately identified as such by the algorithm. However, an excess of "change" pixels 
was classified as "no change", meaning that the user's accuracy of the "change" category ended up being higher than the "no change" category. This is because a pixel identified as "change" is more likely to actually represent a changed area than a "no change" pixel is to represent an unchanged area.

\section{Discussion}

In discriminating between areas of deforestation and no change between the years 1991 and 2000 in the Maya Biosphere Reserve of Petén, Guatemala, the method of differencing the Greenness band of the Kauth-Thomas Tasseled Cap transformations between dates was comparable to the method of differencing the NDVI values between dates. These indices are similar in their heavy reliance on "red edge" of vegetation reflectance, i.e. emphasizing the high differential between the absorption and reflectance of the red and near infra-red bands respectively in vigorous vegetation. Rainforest in one date (1991), followed by an agriculture plot at the end of the dry season during a drought year in the subsequent date (2000), will show a pronounced difference in this measure, a fact reflected by its relatively high accuracy in identifying areas of change. A possible bias may have been introduced favoring these methods, however, in the selection of validation points for setting the thresholding values between change/no change before final production of the change maps. Although we used the NDVI differencing to create a class image for equalized stratified random sampling, we thought that by selecting 12 change classes, a number far in excess of the change classes actually to be represented on the maps, we were not overly privileging the changes as revealed by the NDVI difference image and were rather making a "quick and dirty" classification map for equalized stratified sampling. Although each difference image and PCA band 3 image were all thresholded independently using these validation pixels and maximized for their Kappa coefficient, it is possible that the use of the NDVI difference image privileged the outcome for the NDVI method, and also that of its closely related Greenness component of the BGW transformation. In the future a set of validation points for thresholding could be selected for each technique, although visual inspection and determination of the change classes in each selected pixel was by far the most timeintensive aspect of this project.

\section{Conclusion}

Three change detection algorithms were compared (PCA, BGW differencing, and NDVI differencing), producing a total of five maps (PCA component 3, Brightness difference, Greenness difference, Wetness difference and NDVI difference) representing areas of rainforest in the Maya Biosphere Reserve of Petén, Guatemala which had undergone anthropogenic conversion into non-forested areas. Scenes from the reserve from 1991 and 2000 were compared and classified as changed (forest to unforested) and unchanged. After comparison of their relative accuracies, between-date differencing 


\section{of the Greenness component of the Kauth-Thomas Tasseled Cap Transformation}

proves to have the highest accuracy in revealing areas of change.

\section{References}

BONGAARTS, J. (1996): Population pressure and the food supply system in the developing world. Population and Development Review 22(3), pp. 483-503.

BRANDON, K., WELLS, M. (1992): Planning for People and Parks. World Development 20(4), pp. 557-570.

CARR, D. L. (1999): Un perfil socio-económico y demográfico del Parque Nacional Sierra de Lacandón. Santa Elena, Guatemala, Presidencia de la Republica, Consejo Nacional de Areas Protegidas (CONAP) Secretaria Ejecutiva, The Nature Conservancy/Proyecto de la Biosfera Maya, 69 p.

CARR, D. L. (2002): Rural-frontier migration and deforestation in the Sierra de Lacandón National Park, Guatemala. Ph.D. dissertation. Department of Geography. University of North Carolina. Chapel Hill, $\mathrm{NC}, 327 \mathrm{p}$.

COLLINS, J. B., WOODCOCK, C. E. (1996): An assessment of several linear change detection techniques for mapping forest mortality using multitemporal Landsat TM data. Remote Sensing of Environment 56, pp. 66-77.

CONESE, C., MARACCHI, G. ET AL. (1988): Forest classification by principal component analyses of TM data. International journal of remote sensing 9 (10-11), pp. 1597-1612.

CONGALTON, R. G. (1991): A Review of Assessing the Accuracy of Classifications of Remotely Sensed Data. Remote Sensing of Environment 37, pp. 35-46.

FAO (2005). Forest Resource Assessment. Rome, Food and Agriculture Organization (FAO) of the United Nations.

GEIST, H. J. (1999): Exploring the Entry Points for Political Ecology in the International Research Agenda on Global Environmental Change. Zeitschrift ftir Wirtschaftsgeographie 43(3/4), pp. 158-168.

GEIST, H. J., LAMBIN, E. F. (2001): What drives tropical deforestation? A meta-analysis of proximate and underlying causes of deforestation based on sub-national case study evidence. Louvain-la-Neuve, Belgium, LUCC International Project Office, $116 \mathrm{p}$.

HAYES, D. J., SADER, S. A. (2001): Comparison of change-detection techniques for monitoring tropical forest clearing and vegetation regrowth in a time series. Photogrammetric Engineering and Remote Sensing 67(9), pp. 1067-1075.

LU, D., MAUSEL, P. ET AL. (2004): Change detection techniques. International journal of remote sensing 25(12), pp. 2365-2407.

OJIMA, D., GALVIN, K. ET AL. (1994): The Global Impact of Land-use Change. BioScience 44(5), pp. 300-304.

PARSONS, J. A. (1994): Cultural Geography at Work. Re-reading Cultural Geography. K. E. Foote, P. J. Hugill, K. Mathewson and J. M. Smith. Austin, TX, University of Texas Press, pp. 281-288.

RUDEL, T., ROPER, J. (1996): Regional Patterns and Historical Trends in Tropical Deforestation, 1976-1990. Ambio 25(3), pp. 160-166.

SETO, K., WOODCOCK, C. ET AL. (2002): Monitoring land-use change in the Pearl River Delta using Landsat TM. International journal of remote sensing 23(10), pp. 1985-2004.

TURNER II, B. L., MEYER, W. B. ET AL. (1994): Global Land-Use Land-Cover Change - Towards an Integrated Study. Ambio 23(1), pp. 91-95.

UNITED NATIONS (2001). World Population Monitoring 2001: Population, Development, and the Environment. New York. 
Three change detection algorithms were compared (PCA, BGW differencing, and NDVI differencing), producing a total of five maps (PCA component 3, Brightness difference, Greenness difference, Wetness difference and NDVI difference) representing areas of rainforest in the Maya Biosphere Reserve of Petén, Guatemala which had undergone anthropogenic conversion into non-forested areas. Scenes from the reserve from 1991 and 2000 were compared and classified as changed (forest to unforested) and unchanged. After comparison of their relative accuracies, between-date differencing of the Greenness component of the Kauth-Thomas Tasseled Cap Transformation proves to have the highest accuracy in revealing areas of change.

Laurel Suter, David López-Carr University of California, Santa Barbara,

Department of Geography 1832 Ellison Hall UC Santa Barbara

Santa Barbara, CA 93106-4060 e-mail:laurel@geog.ucsb.edu,carr@geog.ic.ucsb.edu 